\title{
UNA MIRADA A LA POBREZA DESDE EL GÉNERO. CASO DE ESTUDIO: MONTE ALTO
}

\author{
A LOOK AT POVERTY STARTING THE GENRE. CASE STUDY: \\ MONTE ALTO
}

\begin{abstract}
Ania Pupo Vega ${ }^{1}$
"En uno de los países que visité, en lugar de proponerse elevar al máximo el Producto Interno Bruto, las autoridades se trazaron como misión nacional elevar al máximo la Felicidad Nacional Bruta.” Joseph Stiglitz, La Habana, 2002.
\end{abstract}

\begin{abstract}
RESUMEN
El artículo privilegia el enfoque de la pobreza desde la dimensión subjetiva, la cual facilita un acercamiento al ser humano en su individualidad, muchas veces perdida en análisis y estadísticas macro que no permiten develar que la finalidad de los procesos de desarrollo, no es el crecimiento económico en sí, sino el bienestar de las personas, y este tiene que ser vivenciado desde sus dinámicas y referentes individuales. La investigación se realiza en el Consejo Popular Monte Alto, del municipio Buenaventura de la provincia Holguín, el cual muestra vulnerabilidades tanto económicas como sociales y ambientales. Se enfatiza en la importancia de estudiar la pobreza desde las percepciones de las personas, representaciones que deben estar en la génesis de las políticas diseñadas, desde la base, para el afrontamiento al fenómeno.
\end{abstract}

Palabras clave: Desarrollo. Pobreza. Género.

\begin{abstract}
The article focuses on the approach of poverty from the subjective dimension which provides an method to the human being in its individuality, often lost in macro analysis and statistics that do not allow revealing that the purpose of the development process, there is economic growth itself, but the welfare of the people and this has to be experienced from its dynamics and individual referents. The research is conducted in the Consejo Popular Monte Alto, of the Buenaventura, municipality Holguín province, which shows both economic and social vulnerabilities and environmental. It emphasizes the importance of studying poverty from people's perceptions, representations must be in the genesis of policies designed, from the ground, for coping with the phenomenon.
\end{abstract}

Keywords: Development. Poverty. Gender.

\footnotetext{
${ }^{1}$ Estudiante de doctorado en Sociología por la Universidad de la Habana. Máster en Psicología. Licenciada en Psicología. Profesora auxiliar e investigadora del Grupo de Desarrollo Local/Centro de Estudios de Gestión Empresarial, Universidad de Holguín. Email: apvega@fh.uho.edu.cu
} 


\section{Introducción}

Es cada vez más frecuente al hablar del desarrollo no referirse tanto al logro de determinados objetivos económicos de un país, como limitarse a los niveles de pobreza. Se identifica el desarrollo con el afrontamiento de la pobreza y los objetivos se limitan, en ocasiones, a plantearse su reducción.

$\mathrm{Si}$ aún persisten concepciones muy diversas sobre el desarrollo, aunque la evolución de su concepto se enriquece en la medida que asume dimensiones sociales, culturales, subjetivas y se distancia de la absolutización de variables puramente económicas, algo similar ocurre con la conceptualización de la pobreza que, a pesar de no ser un concepto nuevo, los cambios que se introducen, tanto en su conceptualización como en los indicadores para medirla, responden a contextos particulares desde donde se definen sus dinámicas.

El artículo privilegia el enfoque de la pobreza desde la dimensión subjetiva, la cual facilita el acercamiento al ser humano en su individualidad, muchas veces perdida en análisis y estadísticas macro que no permiten develar que la finalidad de todos estos procesos no es el crecimiento económico en sí, sino el bienestar de las personas, que tiene que ser vivenciado desde sus dinámicas individuales.

El estudio se realiza desde la investigación cualitativa, permitiéndonos abordar la pobreza en su multidimensionalidad, en tanto reconoce la existencia de múltiples realidades y captura la perspectiva del objeto investigado; la investigación se concreta en un estudio de caso que examina de manera intensiva la categoría pobreza, mediante la recopilación e interpretación detallada de la información obtenida a través de técnicas cualitativas aplicadas en el trabajo de campo. La aplicación de entrevistas no estructuradas, la observación del contexto y de las prácticas cotidianas fueron valiosas en la comprensión de cómo se vivencia la pobreza. Se hace un análisis desde la perspectiva de género como un prisma interesante y revelador de las inequidades que se encuentran tanto en la génesis de los procesos de empobrecimiento como en la percepción que unas $\mathrm{y}$ otros tienen de la pobreza.

\section{Desarrollo}

El abordaje de la pobreza ha tenido lugar desde múltiples enfoques, lo que ha llevado a diferentes definiciones y propuestas para medirla, demostrándose la complejidad del tema y la necesidad de un enfoque integrador que facilite su comprensión.

La pobreza fue uno de los principales problemas en el siglo XX y se augura que seguirá siéndolo en el actual siglo XXI, aunque existe consenso en entenderla como un fenómeno multidimensional y dinámico, donde se entrecruzan múltiples factores que la condicionan y determinan y que difieren a partir de un período de tiempo y espacio o región determinados.

El Banco Mundial constata esta pluridimensionalidad ${ }^{2}$ al superar su visión de los años ochenta centrada en la renta y los ingresos y poner acento en tres áreas para combatirla a partir de la combinación de aspectos económicos y sociales: promover oportunidades materiales que propicien el crecimiento económico, la creación de trabajos, escuelas, crédito, salud y educación; facilitar el empoderamiento de las personas pobres al fortalecer su participación. Eliminar barreras sociales que resultan de discriminaciones por género, raza, religión o estatus social; mejorar la seguridad de las personas pobres para reducir su vulnerabilidad ante enfermedades, ajustes económicos y desastres naturales.

También el PNUD hace más de una década enfatiza en que para salir de la pobreza se necesita un enfoque multifacético que va más allá de las políticas requeridas para mantener la estabilidad y el crecimiento económico, así como un clima político estable. En coherencia con este planteamiento propone: invertir en el desarrollo humano; ayudar a los pequeños agricultores aincrementar su productividad; invertir en infraestructura; implementar políticas de desarrollo industrial dirigidas a la pequeña y mediana industria; promover la equidad social y los derechos humanos, la sustentabilidad ambiental y la buena gerencia de las ciudades para proveer ambientes seguros.

${ }^{2}$ El Banco Mundial (2001) declara tener en cuenta la educación, la salud, la nutrición y otras áreas del desarrollo humano y en el año 2005 amplía esta visión al incluir desarrollo humano, seguridad, voz y participación. 
De lo anterior se desprende que el problema de la pobreza es multidimensional y debe ser atacado desde diferentes aristas. Por un lado, se deben llevar a cabo políticas de arriba hacia abajo que propicien la estabilidad y el crecimiento económico paralelamente con políticas de abajo hacia arriba que promuevan el desarrollo de las capacidades individuales, mejoren la distribución del ingreso y permitan la participación de las personas pobres en la búsqueda de mejores condiciones de vida.

Lo que se entiende por pobreza no está al margen de una cultura y momento determinados, aspecto que prescribe el propio carácter histórico del concepto y desde ahí su relatividad.

Las visiones económicas asociadas al ingreso o el consumo han estado en el centro de la mayoría de los intentos de definir y medir la pobreza, pero estas han sido enriquecidas y han dado lugar a una gran variedad de conceptos y metodologías. De la definición asumida se desprenderán las propuestas de las metodologías para abordarla, así como las acciones y políticas para su mitigación. Por pobreza se entiende, esencialmente, un estado de carencia, privación, al margen de la teoría desde donde se analice; un intento de clasificarla ha sido entenderla como absoluta o relativa.

\section{Las personas pobres tienen mucho que decir}

Los enfoques que se limitan a las mediciones objetivas han sido mencionados anteriormente, parten de la insuficiencia de recursos económicos para adquirir una canasta mínima socialmente aceptable (pobreza monetaria, de ingreso) o de la inadecuación de las condiciones materiales de vida (necesidades básicas insatisfechas) y no logran captar la dimensión subjetiva del bienestar y de la pobreza. Los comportamientos individuales están movidos por las percepciones y estas varían de persona a persona. Algunas personas u hogares catalogados como no pobres según los criterios del gasto que realizan o de sus ingresos, pueden sentirse pobres. Del mismo modo, las personas u hogares que se encuentran en pobreza objetiva monetaria pueden autopercibirse como no pobres a partir de una línea de pobreza subjetiva como referente.

Por lo tanto, desde el enfoque de pobreza subjetiva - también denominada pobreza como insatisfacción - se considera pobre a quien no le satisface su situación, al considerarse excluido/a de lo que considera el modo normal de vida, con independencia de sus posibilidades económicas. Es decir, a partir de la percepción subjetiva de la persona o del hogar, se ven y autodefinen como pobres.

El análisis subjetivo de la pobreza, es decir, las percepciones que tienen las personas de sus condiciones de vida y del entorno, se ha consolidado tanto teórica como empíricamente, en el estudio de la pobreza. "Escuchar la voz de los pobres, se ha convertido no solo en un imperativo fundamental para mantener la cohesión social sino que también es una requisito en la formulación de programas de lucha contra la pobreza con el fin de lograr una mejor adecuación y eficacia de dichos programas" (BANCO MUNDIAL, 2001).

La idea básica de este tipo de enfoque es ofrecer un diagnóstico alternativo, basado en las percepciones y en las vivencias de la pobreza que experimentan las comunidades y estas son indiscutiblemente singulares en hombres y mujeres.

Las percepciones subjetivas están condicionadas a los contextos cotidianos de las personas, sus historias de vida, sus culturas, y en este sentido son un importante elemento a tener en cuenta en el diseño e implementación de las políticas sociales así como de su impacto.

La pobreza subjetiva o pobreza como insatisfacción, define como pobre a aquella persona que no está satisfecha con su situación, al considerarse excluida de lo que considera el modo normal de vida, con independencia de sus posibilidades económicas. Es una percepción de la persona o del hogar donde se ven como pobres. En este caso, son los sentimientos y las sensaciones de las propias personas los aspectos que determinan si son pobres o no; al contrario de lo que ocurre en la pobreza objetiva, donde quien hace la investigación determina el nivel mínimo de vida.

Son escasos los estudios que parten de la percepción de los pobres. Uno de los más conocidos es "La voz de los pobres: ¿Hay alguien que nos escuche?"3, realizado por el Banco Mundial en 1999,

\footnotetext{
${ }^{3}$ El estudio recoge las voces de 60.000 personas pobres de 60 países; América Latina está representada por Argentina, Bolivia, Ecuador y Perú. Algunas de las principales conclusiones del estudio son: Los pobres describen la falta de alimentos y el desempleo como sus principales problemas; Las personas pobres sienten que el Estado es ineficaz, poco pertinente y corrupto; Las personas pobres hablan de colusión entre los funcionarios y las élites locales;
} 
donde las personas pobres ofrecen sus percepciones sobre lo que es una buena vida y una mala vida, sus problemas y prioridades más angustiantes, la calidad de sus interacciones con las principales instituciones públicas, de mercado y de la sociedad civil y los cambios en las relaciones de género y sociales.

El enfoque ha sido blanco de críticas por parte de los defensores de las medidas objetivas de pobreza, estos argumentan que los individuos no siempre son los mejores jueces de lo que es mejor para ellos, por lo tanto se puede llegar a sobrevalorar o subvalorar el consumo de algunos bienes, lo que conduce a evaluaciones contrarias en cuanto quienes son pobres.

Conocer qué piensan las personas sobre sus condiciones y causas de pobreza son un valioso aporte al diseño de las políticas para su mitigación, el valor de sus vivencias y las estrategias de afrontamiento diseñadas desde sus hogares devienen en un referente indispensable para la implementación de acciones, quienes viven una situación y entienden que esta puede ser mejorada, siempre tienen una visión de cómo hacerlo aun cuando la solución desborda sus competencias individuales. A partir del bienestar percibido por las personas, bienestar subjetivo, se plantea que la persona es quien mejor enjuicia y define su bienestar.

La presentación de diversos enfoques con relación a la pobreza nos da la medida de la variedad de conceptos y propuestas para medirla y erradicarla, y nos aproxima a una comprensión de su complejidad. La virtud de estas miradas es develar las pobrezas que existen y las disímiles maneras de implementar su afrontamiento.

Las controversias proyectadas con relación al fenómeno de la pobreza tienen lugar a partir de los enfoques mantenidos tanto por prestigiosos organismos internacionales ${ }^{4}$ como por instituciones

Aunque algunas personas pobres reconocen la labor positiva de las ONG, también se habla de la ineficacia, la falta de pertinencia y el favoritismo de éstas; Las personas pobres consideran que las redes informales y las asociaciones son cruciales para su supervivencia y se convierten en una especie de salvavidas; Las personas pobres informan que viven en un entorno de mayor delincuencia, corrupción, violencia e inseguridad. Además, consideran que las oportunidades solo están disponibles para los ricos, lo que perpetúa el ciclo vicioso de exclusión. Finalmente, el estudio concluye que una estrategia para el cambio debe tener cuatro componentes: (1) Partir de las realidades de las personas pobres. (2) Invertir en la capacidad de organización de los pobres. (3) Cambiar las normas sociales y (4) Apoyar a los empresarios que fomenten el desarrollo (NARAYAN, DEEPA, 1999).

${ }^{4}$ Así por ejemplo el Banco Mundial, que tradicionalmente ha tenido una políticas y académicas desde donde se construyen indicadores y metodologías para diferentes contextos en busca de informaciones equiparadas para los análisis sociales y se definen diseños y estrategias para su mitigación o erradicación.

Con fines de comparación internacional, el Banco Mundial calcula líneas de pobreza internacionales de $\$ 1$ y $\$ 2$, en términos de la Paridad de Poder de Compra (PPC) de 1993, donde la PPC mide el poder de compra relativo de las monedas de los países. De esta manera, las líneas de pobreza se expresan en una unidad común para todos los países. $\mathrm{Se}$ consideran en pobreza absoluta todas aquellas personas que viven con menos de $\$ 1$ diario y en pobreza relativa aquellas que viven con menos de $\$ 2$ diarios.

\section{Procesos de empobrecimiento atravesados por la perspectiva de género.}

Las estadísticas actuales declaran que la mayoría de las personas pobres en el mundo son mujeres, también nos dicen que las mujeres no se benefician automáticamente de los programas y las estrategias de lucha contra la pobreza y que, incluso en ocasiones, las acciones que promueven el crecimiento pueden empeorar ${ }^{5}$ la situación de las mujeres empobrecidas, sino se tienen en cuenta desde los diseños metodológicos aplicados. Estas aseveraciones están reclamando una mirada desde el género a los procesos de empobrecimiento en los discursos del desarrollo.

El tema de la mujer y la pobreza comienza a tomar fuerza a finales de la década de los 70 del pasado siglo, desde diferentes posturas teóricas y metodológicas; las aportaciones más recientes declaran el dinamismo de esta relación desde donde puede ser analizado con mayor agudeza y objetividad.

\footnotetext{
visión dirigida hacia el aumento de la renta nacional, pone énfasis en la eliminación de la pobreza y declara que su objetivo es erradicarla (BANCO MUNDIAL, 2005), parte de definir un umbral para clasificar a las personas pobres de las que no lo son, modifica sus parámetros para definir la pobreza, situaba anteriormente en el dólar diario de ingresos, y propone 1,25 dólares por persona y día, lo que aumentó considerablemente la cifra de personas consideradas pobres.

${ }^{5}$ Cuando las estrategias son mal diseñadas y conducidas, se reproduce la desigualdad de oportunidades y con ellas las diferencias de género; no en pocas ocasiones, con la intención (más que el conocimiento) de lograr la equidad, se han incrementado las desigualdades debido al mal manejo de las políticas de desarrollo que en algunos casos, siguen caracterizándose por el asistencialismo y estar ciegas al género
} 
Las teorías sobre el desarrollo que marcaron los años 50 y 60, ignoraron el papel de las mujeres en estos procesos. La introducción de la perspectiva de género en los análisis de los procesos de empobrecimiento ha significado un viraje rotundo en los mismos, en la medida en que ha puesto acento a la complejidad y multidimensionalidad de estos procesos y a los efectos derivados de las diferencias de género. En definitiva no se trata de ver que las mujeres son pobres (o más pobres que los hombres), sino que la pobreza está condicionada por el género (MATEO, 2001) y este condicionamiento está en la base de las dinámicas sociales y familiares que exponen a las mujeres a situaciones de franca desventaja. Según Razavi (apud ESPINAR, 2004, p. 62), la perspectiva de género aplicada a los estudios de pobreza debe centrarse en analizar cómo las diferencias de género afectan a los mecanismos sociales que conducen a situaciones de pobreza.

La pobreza ha sido abordada desde diversas metodologías y son muchas las propuestas de técnicas y herramientas diseñadas para su medición; entender que la pobreza es percibida, vivida y afrontada de manera diferente por unas y otros, exige un análisis de estas técnicas y metodologías, una evaluación de sus ventajas y desventajas y la generación, sobre este análisis, de nuevas mediciones que las complementen o superen.

Uno de los métodos más utilizados ha sido la medición de la pobreza a partir del ingreso del hogar, el cual resulta un indicador cuantitativo ${ }^{6}$ (en términos monetarios) indiscutiblemente muy efectivo para el diagnóstico de situaciones de pobreza y útil en las comparaciones entre países y territorios, pero limitado para evaluar las dimensiones de género expresadas hacia el interior del hogar.

La principal debilidad de las medidas basadas en los ingresos radica en no abarcar la pobreza en esas múltiples dimensiones donde se reflejan elementos culturales y simbólicos reveladores de las relaciones que subordinan a la mujer e invisibilizan su trabajo, como las dinámicas que tienen lugar al interior de los hogares; estas dinámicas permiten además analizar las diferencias entre hombres y mujeres con relación a la vivencia de la pobreza, el empleo del tiempo y

\footnotetext{
${ }^{6}$ Son más frecuentes los estudios con el uso de indicadores monetarios que de otros enfoques como el de las capacidades, la participación, las percepciones subjetivas, la exclusión social.
}

la distribución de los recursos, que no siempre es equitativa.

En este sentido, los argumentos de Amartya Sen nos resultan muy valiosos, advierte que las diferencias entre los géneros no es esencialmente una cuestión de diferencias de ingresos como de libertades desiguales por lo que no le resulta suficiente analizar las diferencias de ingresos ni su distribución al interior de los hogares y propone centrarse en el grado de satisfacción de las necesidades y de bienestar realmente alcanzado por unos y otras.

El interés por visibilizar las posiciones desventajosas en que se encuentran las mujeres y que se agudizan en los contextos más empobrecidos, se ha plasmado en las agendas de organizaciones internacionales como la Plataforma de Acción aprobada por la Cuarta Conferencia Mundial sobre la Mujer, celebrada en Beijing en 1995, donde se incluye la pobreza de las mujeres dentro de las esferas que necesitan una atención especial por parte de la comunidad internacional, los gobiernos y la sociedad civil.

En ese mismo año, 1995, el PNUD ofrece en sus informes anuales sobre desarrollo humano, un índice que primeramente llamaron Índice de Potenciación de la Mujer, y más tarde, Índice de Potenciación de Género (IPG), por lo que en sus análisis se incluye a hombres y mujeres. Este indicador toma en cuenta la participación de la mujer en la vida económica y política y resulta de especial interés en la comparación de la distribución del IDH y del IPG para un mismo país y un mismo año para comprender la dimensión de género en los procesos de empobrecimiento o en el desarrollo humano, aunque es censurable la naturaleza cuantitativa de sus datos.

En 1996, la Comisión de la Condición Jurídica y Social de la Mujer de las Naciones Unidas ${ }^{7}$ debatió la cuestión relativa a la mujer y la pobreza y propuso la adopción de nuevas medidas por parte de sus Estados Miembros y la comunidad internacional. Dentro de estas se contempla que todas las políticas y los programas orientados a la erradicación de la pobreza deben incluir la perspectiva de género.

\footnotetext{
Se declararon medidas encaminadas a la adopción de políticas que garantizaran la protección económica y social adecuada a las mujeres durante los períodos de desempleo, enfermedad, maternidad, gestación, viudez, discapacidad y vejez; y que las mujeres, los hombres y la sociedad compartieran las responsabilidades por el cuidado de los niños y de otras personas a cargo.
} 
En la actualidad, el reto consiste en encontrar indicadores dinámicos sobre el empobrecimiento que no excluyan las variables económicas sino que la sumen a otras variables sociales, políticas y culturales, que recojan las formas de exclusión basadas en el género observables en las unidades domésticas, sin perder la dimensión política del Estado. Indicadores construidos a partir de los implicados y sobre todo de las implicadas, ausentes en la historia de la medición de la pobreza hasta hace relativamente poco tiempo (TORTOSA, 2001).

La experiencia que las mujeres tienen de la pobreza puede ser diferente y más aguda que la de los hombres debido a formas de exclusión basadas en el género, a partir del cual se construyen desigualdades que no siempre se aprecian a simple vista, se encuentran muchas veces incorporadas a la cultura y desde esta, naturalizadas.

La pobreza femenina se relaciona fuertemente con factores culturales y cualitativos, tiene un carácter relacional en tanto depende del lugar que ocupan las mujeres en el entramado de relaciones en los espacios a nivel macro y micro. En la organización de la sociedad las mujeres se encuentran en un espacio de subordinación, pero el análisis de género desborda lo puramente estructural para entrar en un aspecto mucho más complejo y determinante: las relaciones de poder. Este análisis nos lleva a entender que encontrarse en posiciones de subordinación implica menores oportunidades de ejercer el poder y limitaciones en la toma de decisiones, lo cual ocurre tanto en el ámbito público como en el privado.

Son muchas las causas, desde lo cultural, que conforman las asimetrías entre los géneros; la división sexual del trabajo tiene mucho peso en este sentido. A partir de esta división, las actividades realizadas por las mujeres ocurren al interior de los hogares, no se remuneran, no se consideran trabajo y por tanto, no se valorizan ni visibilizan ante la sociedad, entendiéndose como asignada "naturalmente" y ante las que no queda margen para la elección.

Toda mujer que trabaja remuneradamente convive con una mujer dedicada a la vida doméstica, en menor o mayor medida, con un valor simbólico mayor o menor, pero siempre en la dualidad. En este sentido asevera Tortosa (2001) que la vida de las mujeres está afectada por la devaluación cultural de lo femenino. La oposición trabajo/familia expresa así la identificación prioritaria de la mujer con la familia y por tanto con lo privado y del hombre con el ámbito laboral y público.

El trabajo doméstico no remunerado no se cuenta como ingreso pero puede hacer una diferencia considerable en el ingreso del hogar (BATTHYÁNY, 2005), por lo que resulta imprescindible tenerlo en cuenta en los estudios de género y pobreza para visibilizar y valorizar su aporte en las dinámicas domésticas.

Una forma de visualizar el trabajo doméstico no remunerado $^{8}$ es cuantificar el tiempo que se le dedica a su realización (dentro del volumen de la carga de trabajo) dado que abarca todas las actividades de mantenimiento y reproducción de la vida. Los estudios sobre el uso del tiempo son relativamente recientes en países latinoamericanos, se conocen los resultados de encuestas aplicadas en Cuba9 , 2001, México, 2002, Chile, 2007, Venezuela, 2009 y Uruguay, 2003 en Montevideo y en el área metropolitana, y en 2007, una encuesta nacional), entre otros (MILOSAVLJEVIC, MIRIAM, 2008).

La falta de tiempo atraviesa la vida de las mujeres en todas las direcciones. La dedicación a las actividades domésticas y el cuidado de personas a su cargo, limita sus espacios para el ocio, el desarrollo personal o actividades personalmente atractivas; también repercute en su participación en actividades políticas, sindicales, sociales, comunitarias, donde no pocas veces las propias mujeres se autolimitan si estos otros espacios entran en conflicto con sus vidas familiares; en estos casos generalmente se privilegian las actividades familiares.

Para superar estas desigualdades y apuntar a un desarrollo en el que todos los grupos sociales, sin distinción, contribuyan a su sostenimiento, es preciso avanzar hacia un cambio cultural, cambio que solo es posible con el desarrollo de una conciencia social frente al tema o una masa crítica que reconozca las desigualdades y dé cuenta de la necesidad de superarlas, emprendiendo acciones concretas (ARIAS, 2008).

El paradigma de desarrollo que se propone con la introducción del Enfoque Género en el

\footnotetext{
${ }^{8}$ Existen propuestas de medirlo y asignarle valores monetarios en aras de hacer valoraciones sobre su contribución al PIB.

9 Para ver los resultados: Encuesta sobre el Uso del Tiempo (Cuba, 2001) disponible en: http://www.one.cu/publicaciones/ enfoquegenero/tiempo/eut.pdf
} 
Desarrollo (GED) tiene necesariamente que desmontar las actuales relaciones de poder basadas en la subordinación femenina y apostar por el empoderamiento ${ }^{10} \mathrm{y}$ fortalecimiento social, económico y político de las mujeres desde la conformación de una sociedad democrática.

En las últimas décadas ha sido prioridad, en los programas de desarrollo, incorporar el enfoque GED a sus proyectos por la necesidad de empoderar a las mujeres para que se beneficien de los avances del desarrollo, utilizando su potencial en los diferentes momentos de los proyectos. De esta forma, el concepto empoderamiento deviene categoría de orden en los estudios de género actuales, incluida nuestra investigación.

Al decir de León (1997b), el concepto se utiliza como sustituto de integración, participación, autonomía, identidad, desarrollo y plantación, y no siempre referido a su origen emancipador. El rasgo más sobresaliente del término empoderamiento, sin dudas es contener la palabra poder, de manera que su uso es llamado de atención del poder como relación social. Las relaciones de poder pueden, entonces, significar dominación como también desafío y resistencia a las fuentes de poder existentes o servir para obtener control sobre ellas (LEÓN, 1997a). Por decirlo de otra forma, no se trata de ver que las mujeres son pobres, sino que la pobreza está condicionada por el género.

\section{La comunidad de Monte Alto como caso de estudio}

\section{Características sociodemográficas}

La población del CP es 2228 habitantes, de ellos 1052 hombres y 832 mujeres. El espacio ha ido perdiendo su población más joven que sale en busca de mejores condiciones de vida, y al igual que otros espacios rurales, le es característica la masculinización y el envejecimiento así como

\footnotetext{
${ }^{10}$ Las interpretaciones y destinos dados al concepto de "empoderamiento" varían de acuerdo a las ciencias que lo utilizan, entre las que más lo emplean están la ciencia sociológica, la psicológica, la antropológica, las ciencias políticas, de la educación, el derecho y la economía, pero han sido los estudios de la mujer y el género, y específicamente en el campo de Género en Desarrollo, quienes han utilizado este concepto en gran parte de su discurso. El feminismo ha utilizado el término basándose fundamentalmente en la idea de poder, tanto para los movimientos sociales como para la teoría de las ciencias sociales en las últimas décadas.
}

procesos de concentración de la población anteriormente dispersa en busca fundamentalmente de la energía eléctrica. Unas 150 personas clasifican en la tercera edad, por el momento sigue predominando la población económicamente activa. Por el color de la piel la población es mayoritariamente blanca.

Las principales problemáticas del consejo se relacionan con el deterioro de su entorno socioambiental, la precariedad de sus condiciones y calidad de vida.Entre ellas se enumeran:

- La calidad del agua, (de seis circunscripciones, sólo una tiene agua potable, el resto debe buscarla entre 6 y $10 \mathrm{~km}$ ).

- La ausencia de electricidad afecta población en siete asentamientos (unas 31 viviendas). En la mayoría de las casas la energía usada para cocinar es la leña, con sus implicaciones para el medio ambiente y la salud de las mujeres quienes parecen coronadas por la cultura a ser dueñas de ese espacio y que además son responsables por la búsquela de la leña.

- El deterioro creciente de los caminos, intransitables en épocas de lluvia, lo que tiene su impacto en el traslado de la producción, y la satisfacción de necesidades de la población dado lo alejado de los asentamientos del núcleo del CP. Las más perjudicadas son las mujeres pues los principales medios para trasladarse, como caballos, volantas, tractores, carretones, están en manos de los hombres.

- Situación de su fondo habitacional, considerada como típicos bohíos en un alto por ciento. Téngase en cuenta que de 844 viviendas, 374 tienen piso de tierra y solo clasifican en tipología I, 25 viviendas.

- Las prácticas agropecuarias tradicionales, sumado a uso de métodos verticalistas en el extensionismo rural y la falta de una cultura ambiental en los productores, inciden en la baja sustentabilidad económica y socioambiental de estos espacios. La agresividad hacia el medio ambiente, denota la ineficacia de la estrategia ambiental y la falta de articulación entre los actores locales para enfrentarlo.

- Hay otros problemas, como el alcoholismo en su población masculina adulta, la violencia 
social y contra las mujeres. Las enfermedades más frecuentes son la diabetes y la hipertensión y cáncer de próstata.

\section{Perfil de la mujer en el CP}

La población femenina se encuentra mayoritariamente sin vínculo laboral y en condiciones de extrema vulnerabilidad económica y social, con bajos niveles educativos, así como dificultades en el acceso con calidad a los servicios sociales. A ello se le añade el fenómeno de la violencia contra la mujer, que en sus disímiles expresiones, repercute negativamente en el diseño de sus estrategias de vida y consiguientemente en todas las relaciones familiares.

La visión tradicional sobre el desarrollo rural invisibiliza el trabajo realizado por las mujeres en la reproducción de la vida cotidiana de sus familias, en la producción agropecuaria.

En el CP solo 34 mujeres tienen ingresos a partir del empleo o autoempleo: 19 son obreras agrícolas, 15 trabajan en comercio, nueve en el sector de educación, seis en el Consultorio Médico de la Familia y cuatro lo hacen por cuenta propia. El resto se autodefine como ama de casa y considera su trabajo como ayuda, la mayoría no cuenta con ingresos propios.

\section{Algunos resultados}

Se entrevistaron 13 mujeres y 12 hombres; la mayoría se encuentra entre 21 y 35 años, la entrada per capita es de 204.00 pesos.

Con relación al salario solo una persona proyecta conformidad con su salario actual, la gran mayoría reconoce que no es suficiente, que solo alcanza escasamente para la alimentación y para pagar la electricidad y el pago a otros servicios esenciales; en varias personas entrevistadas destaca el hecho de las deudas contraídas durante el mes para la satisfacción de necesidades elementales "cuando cobro lo debo todo", "cobro para pagar las deudas", esta situación remarca la idea de una organización presentista de la vida y proyectos poco elaborados sobre metas a muy corto plazo, los préstamos llegan a constituirse en estrategias de subsistencia que repiten el círculo y reproducen las condiciones de precariedad.

La gran mayoría de las personas entrevistadas refieren que duplicarían o triplicarían la entrada actual de dinero solo para llegar a tener un nivel de vida considerado adecuado; para no sentirse pobres necesitarían mucho más porque refieren que son muchas las carencias, desde el patrimonio material ${ }^{11}$, que en la mayoría es precario, se destacan las malas condiciones de las viviendas y los escasos y deteriorados muebles y otros utensilios y set del hogar; en este aspecto nos interesa profundizar que este patrimonio generalmente ha pasado de generación a generación, no como consecuencia de una descapitalización de la familia, sino que hay una reproducción de estos niveles de vida y en el caso de las parejas que conforman nuevos hogares, casas hechas con muy malas condiciones constructivas, no tienen posibilidad de amueblarlas funcional ni estéticamente, por lo que cuentan con un elemental y básico patrimonio, generalmente deteriorado y precario.

La referencia a la falta de equipos electrodomésticos, como refrigeradores, televisores y lavadoras, son generalmente un reclamo de las mujeres dado que dificulta las dinámicas domésticas y complejizan el trabajo dentro de los hogares, fundamentalmente desarrollados por ellas, que en el contexto estudiado, la mayoría son amas de casa. Otros equipos demandados son los teléfonos fijos y celulares, computadoras y vídeos y el acceso a internet.

Llama la atención que algunas personas declaran no haber pensado nunca en lo que necesitarían para dejar de sentirse pobres, esto pudiera estar hablando de las escasas elaboraciones de futuro y del planteamiento de metas a corto plazo que se configuran para las estrategias de subsistencia que son las que prevalecen en estas personas; otro elemento que influye desde las subjetividades es la familiarización acrítica con las condiciones en las que viven, la naturalización y el acostumbramiento al fenómeno que pueden incidir en la objetividad de los análisis. En muchas ocasiones entran en juego mecanismos de negación.

\footnotetext{
${ }^{11}$ Nos referimos tanto al patrimonio construido, que en este caso son las viviendas, como al patrimonio mueble, conformado por los muebles, utensilios y otros útiles del hogar.
} 
En cuanto a quiénes son las personas en las que más se revierten los ingresos dentro del hogar, es de destacar que la mayoría refiere los niños y niñas; en encuestas respondidas por mujeres ellas reconocen ser las que más lo necesitan, en algunas respondidas por hombres privilegian a los/as pequeños/as y a sus esposas y solo dos consideran que son ellos quienes más lo necesitan, estos resultados pudieran estar mostrando cómo se mueven los patrones tradicionales al interior de los hogares y cómo las mujeres ganan en autovaloración y en valoración de la propia familia.

Solo tres personas no se sienten pobres, dos de ellas declaran que son "necesitadas", con esto constatamos una resistencia a la categoría pobreza que pudiera estar asociada a ideas de inferiorización dentro de la comunidad, aunque reconocen la "necesidad" asociándola a la dimensión económica; en este sentido los planteamientos más comunes son: "económicamente sí, porque no tengo nada ..." "no tengo dinero para satisfacer mis necesidades y las de mis hijos", otras expresiones repetidas centradas en las limitaciones económicas fueron: "no es una pobreza extrema pero con mi salario no puedo acceder a un buen nivel de vida", " mis niños tienen muchas limitaciones económicas, lo que lleva a que no puedan tener distracción ni comodidades".

Con relación a los bienes y servicios a los que necesitaría acceder para no sentirse pobres se declaran en primer orden los relacionados con la alimentación y la mejora de las condiciones de sus viviendas, en segunda opción la adquisición de ropas y calzados, equipos electrodomésticos y el acceso a instalaciones turísticas para la recreación y el ocio; una minoría se refiere al acceso a opciones de educación y cultura y otras al acceso a la telefonía móvil, internet, lo cual resulta un detalle llamativo si tenemos en cuenta que no tienen satisfechas las necesidades básicas o mínimas ni han instrumentado estrategias para la satisfacción de las mismas; dos personas sitúan en primerísimo lugar la electrificación de la vivienda porque aun su asentamiento no cuenta con este servicio.

\section{Ideas conclusivas}

Estudiar la pobreza desde las percepciones de las personas ofrece un cúmulo de informaciones y representaciones importantes con relación al fenómeno que pudieran situarse en la génesis de políticas diseñadas desde abajo, además de constituirse en termómetro de la problemática de la pobreza y cómo es vivenciada en el contexto de estudio.

El estudio de estos hogares en condiciones de pobreza es importante además dado que:

[...] la precariedad económica es uno de los factores que pueden contribuir a la exclusión social, y puede existir en germen, la formación de un modo de vida en el que alrededor de la condición de pobreza se desarrolle una organización de la vida familiar con componentes de marginalidad, exclusión y desconexión social, con prevalencia de conductas adaptativas y pasivas, que constituya en sí mismo un riesgo no solo social, sino también psicológico para las presentes y futuras generaciones de estas familias. (ZABALA, 1993).

Atravesar estos análisis por una perspectiva de género permite constatar las diferencias en la manera de vivir y percibir el fenómeno por hombres y mujeres, información útil además para el diseño e implementación de acciones afirmativas para los grupos más vulnerables, en este caso las mujeres, no solo las jefas de hogar que conviven con sus hijos sin otros apoyos, sino también la que trabaja sin remuneración y por tanto es dependiente económicamente de su pareja, y además no tienen un capital cultural que les permita emprender el trabajo remunerado con una estrategia.

La profundización de los estudios de pobreza en espacios académicos contribuye a la socialización de los resultados, aspecto que visibiliza el fenómeno.

\section{Referencias}

AGUADO, L. y OSORIO, A. Percepción subjetiva de los pobres: Una alternativa a la medición de la pobreza. En Reflexión Política, v.8, n.15, p.26-40, 2006. Disponible en: http://www.redalyc.org/pdf/110/11001503.pdf.

ARIAS, M. Género en el desarrollo: realidades y desafíos a través de un estudio de caso. En Estudios sobre desarrollo local, innovación social y género. La Habana: Academia. P. $68-78,2008$.

BATTHYÁNY, K.; SOL, M.; DEDE, G.; MACADAR, D.; PARDO, I. Género y pobreza: un caso de desigualdades. 2005. Disponible en: www.socialwatch.org/node/11609 
CAStillo, M., CASTro, G., GONZÁleZ, O. A. Los hijos e hijas yla percepción de pobreza en hogares caleños. En Revista Latinoamericana de Ciencias Sociales - Niñez y Juventud, 2 (9), p. 573 -588, 2011.

CHÁVEZ, E. El combate contra la pobreza en Cuba. Políticas públicas y estrategias familiares. En Seminario Internacional: "El rol del Estado en la lucha contra la pobreza”. Recife, Brasil, 2003.

CRUZ, J. y TORRES, J. ¿De qué depende la satisfacción subjetiva de los colombianos? En Cuadernos de Economía, 25(45), p.131-154, 2006.

DÍAZ, G. Bienestar subjetivo. Actualidad y perspectivas. En Revista Cubana de Medicina General Integral, 17(6), p.572-579, 2001.

DUBOIS, A. Convergencias y divergencias sobre el concepto de pobreza. En Federación de Cajas de Ahorro Vasco-Navarras. Pobreza y solidaridad: hacia un desarrollo sostenible. Vitoria-Gasteiz: Cajas de Ahorro Vasco-Navarras. p.157-173, 2006.

ESPINA, M. Políticas de atención a la pobreza y la desigualdad. Buenos Aires: Consejo Latinoamericano de Ciencias Sociales - CLACSO, 2008.

ESPINAR, E. Violencia de género y los procesos de empobrecimiento. Estudio de la violencia contra las mujeres por parte de su pareja o ex-pareja sentimental. Tesis Doctoral. Universidad de Alicante, 2004.

GONZÁLEZ, E. Los límites del desarrollo rural en América Latina: evolución histórica. Universidad de La Habana, 2001.

GONZÁLEZ, M. Algunas reflexiones en torno a las diferencias de género y pobreza. En: Tortosa, J. (Coord). Pobreza y perspectiva de género. (87-112). España: Icaria, 2001.

GIARRIZZO, V. Pobreza subjetiva en Argentina. Construcción de indicadores de bienestar económico. Tesis de Doctorado. Facultad de Ciencias económicas. Universidad de Buenos Aires, 2007. Disponible en: http://www.econ.uba. ar/www/servicios/Biblioteca/bibliotecadigital/bd/tesis_doc/ giarrizzo.pdf

IÑIGUEZ, L. Heterogeneidad territorial de Cuba entre herencias y renovaciones. En: EVERLENY, O., VIDAL, P., NOVA, A. y IÑIGUEZ, L. Miradas a la economía cubana. (101-109). La Habana: Caminos, 2009.

Instituto Nacional de Estadísticas. Enfoque estadístico. Encuesta Exploratoria de Uso del Tiempo en el gran Santiago. Uso del tiempo. ¿Cómo distribuyen el tiempo hombres y mujeres en el gran Santiago? 2009. Disponible en: http://www.ine.cl.

LABRADA, C. Desarrollo local. Un estudio de caso en el municipio "Rafael Freyre", provincia Holguín. Tesis de Doctorado. Facultad de Sociología Universidad de La Habana, 2008.

LAGARDE, M. Multidimensionalidad de la categoría género y del feminismo. En: González Marín, María Luisa (Coord). Metodología para los estudios de género. México: UNAM, p.48-71. 1996.

LAMAS, M. Usos, dificultades y posibilidades de la categoría 'género'. En LAMAS, M. (comp). El género: la construcción cultural de la diferencia sexual. México: Miguel Ángel. Porrúa, 2000.

LEÓN, M. Poder y empoderamiento de las mujeres. Colombia: Tercer Mundo Editores, 1997a.

Empoderamiento: relaciones de las mujeres con el poder. En Revista Foro, 33, diciembre, 1997b

MASSOLO, A. Las mujeres y el hábitat popular: ¿cooperación para la sobrevivencia o para el desarrollo? En Hojas de Warmi. 10 (1), p.79-89, 1999.

MATEO, M. Desiguales, pobres y excluidas. Lecciones metodológicas desde la (ausente) perspectiva de género. En: Papers. 65 (1), p. 167-179, 2001.

MATEO, M. A. y ESPINAR, E. Dinámicas del empobrecimiento desde la perspectiva del género. En Revista Internacional de Sociología. 28, 2001. Disponible en: <http://www.siis.net/documentos/he/EGU24.pdf>.

MilOSAVLJEVIC, M. Panorama sobre las encuestas de uso del tiempo en América Latina. En VI Reunión internacional de expertas y expertos en encuestas sobre uso del tiempo. Disponible en: $<$ http://cedoc.inmujeres. gob.mx/documentos_download/101019.pdf >. División de asuntos de la CEPAL, Julio 2008.

NUSSBAUM, M. Las mujeres y el desarrollo humano. Barcelona: Herder, 2011.

SEN, A. Sobre Conceptos y medidas de pobreza. Los conceptos de la pobreza. En Comercio Exterior. 42 (4), 1992.

Teorías del desarrollo a principios del siglo XXI. En Cuadernos de Economía, 17 (29), p.73-100, 1998.

SEN, G. El empoderamiento como un enfoque a la pobreza. En ARRIAGADA, I. y C. TORRES (comps). Género y pobreza. Nuevas dimensiones, Ediciones de las Mujeres, $\mathrm{N}^{\circ}$ 26, Santiago de Chile, ISIS Internacional, 1998.

TORTOSA, J. Medidas de la pobreza: historia de una ausencia. Páginas. En: _ (Coord.). Pobreza y perspectiva de género. España: Icaria, p.15 - 31, 2001.

ZABALA, M. Familia y pobreza en Cuba. Estudio de casos. La Habana: Acuario, 2010.

Recebido em 25 de outubro de 2013

Aceito em 1 de novembro de 2013 